IFN Working Paper No. 993, 2013

\title{
Topping up and the Political Support for Social Insurance
}

\author{
Andreas Bergh
}




\title{
TOPPING UP AND THE POLITICAL SUPPORT FOR SOCIAL INSURANCE
}

\author{
ANDREAS BERGH \\ the Research Institute of Industrial Economics, \\ P.O. Box 55665, SE-102 15 Stockholm, Sweden. \\ Email: Andreas.Bergh@ifn.se. \\ Financial support from the Jan Wallander and Tom Hedelius Foundation \\ is greatfully acknowledged.

\begin{abstract}
This paper analyzes how the possibility to complement social income insurance schemes with private insurance affects the political support for social insurance. It is shown that political support for social insurance is weakly decreasing in the replacement rate. Policy makers seeking to maintain support for social insurance schemes can do so by lowering the replacement rate and allowing topping up contracts. The strategy is likely to be a partial explanation for the continued political support for welfare states with universal social insurance schemes such as those in Scandinavia.
\end{abstract}

JEL classification: H53, D72

Keywords: Social insurance, Topping up, redistribution. 


\section{IntRoduction}

In modern welfare states, it is increasingly common that citizens top up publicly financed benefits with privately financed benefits. In the Scandinavian welfare states with their extensive ranges of positively income-related (Bismarckian) social insurance schemes, that replaces income lost due to for example retirement, sickness and unemployment, topping up means that social insurance coverage is a complemented with private or occupationally negotiated insurance schemes. This note analyzes how such topping up contracts affect the political support for Bismarckian social insurance.

Theoretically, several mechanisms can explain political support for mandatory social insurance schemes. For example, when individuals are risk avert and private insurance markets are inefficient due to adverse selection, even (some) ex-post monetary net-contributors may be better off with social insurance compared to market insurance (Casamatta et al., 2000). This mechanism is however counteracted by the fact that social insurance typically pools risks, resulting in a redistribution from low-risk groups to high-risk groups (Bergh, 2005). Thus, the political support for social insurance depends negatively on the degree of vertical income redistribution within social insurance and negatively on the efficiency of market insurance.

This paper presents a simple model for analyzing the relationship between social insurance replacement rate, topping up contracts and political support. It complements the findings in Gouveia (1997) and Epple and Romano (1996) where it is shown that a majority will typically support a mixed system of provision of goods such as health care, such that individuals can add private goods to publicly financed goods. Another related paper is Petretto (1999), who uses a model similar to the one presented in this paper, but with some important differences. Petretto focus on utilitarian welfare maximizing policies, whereas the present paper studies political support. Moreover, Petretto considers a health insurance that covers expenditures for health care, whereas the contribution of this paper is to analyze political support for a stylized Bismarckian income replacement social insurance. It is shown that topping up weakly increases the political support for social insurance, and that there are plausible cases where social insurance has majority support only of topping up is allowed. Though highly stylized, the mechanism captured by the model helps to explain the continued political support for the relatively extensive social insurance schemes typically seen in the scandinavian welfare states.

\section{THE MODEL}

Assume that society consists of $N$ individuals, with ordered incomes $y_{1}<\ldots<$ $y_{N}$ and corresponding risks $\rho_{i \in[1, N]}$. The risk is the probability of being in state loss, in which the individual cannot earn income and instead receives from social insurance a proportion $r$ of her previous income. ${ }^{1}$ The tax rate needed to finance

\footnotetext{
${ }^{1}$ Attention is thus restricted to universal policies where all agents are given the same replacement rate.
} 
the social insurance replacement rate $r$ is $t$, derived by assuming a balanced social insurance budget:

$$
\begin{aligned}
t \sum_{i=1}^{N} y_{i}\left(1-\rho_{i}\right) & =r \sum_{i=1}^{N} y_{i} \rho_{i} \Leftrightarrow \\
t & =r \frac{\sum_{i=1}^{N} y_{i} \rho_{i}}{\sum_{i=1}^{N} y_{i}\left(1-\rho_{i}\right)} .
\end{aligned}
$$

Each individual $i$ has preferences $\succsim_{i}$ over three constitutions: pure social insurance (S), social insurance with topping up (T) and market insurance (M). The ordinal preferences of an individual over these constitutions are easily described by ordering the alternatives from the most to the least preferred, for example TSM. Each agent ranks the three alternatives according to their expected utility. The expected utility from social insurance is

$$
E U_{i}^{S}=\left(1-\rho_{i}\right) u\left(y_{i}(1-t)\right)+\rho_{i} u\left(r y_{i}\right), \text { with } u^{\prime}>0, u^{\prime \prime}<0 .
$$

Note that benefits are not subjected to taxation, though this assumption is not important for the results.

To model market insurance, assume that $q_{i}^{M}$ is the utility maximizing amount of insurance bought by $i$ when the premium is $a$. It is assumed that private firms can handle the adverse selection problem by using a costly risk discrimination technology. The premium is determined by a multiplicative markup $c \geq 1$ over the actuarially fair premium, where $c$ reflects both imperfect competition and the costs private firms incur to obtain information about individual risks. Using this notation, expected utility from market insurance will be

$$
E U_{i}^{M}=\left(1-\rho_{i}\right) u\left(y_{i}-a_{i}\right)+\rho_{i} u\left(q_{i}^{M}\right),
$$

where

$$
q_{i}^{M}=\arg \max _{q_{i}}\left(1-\rho_{i}\right) u\left(y_{i}-a_{i}\right)+\rho_{i} u\left(q_{i}\right), \text { and } a_{i}=\frac{q_{i} c \rho_{i}}{1-\rho_{i}} .
$$

Finally, expected utility from constitution T, social insurance with topping up, will be

$$
E U_{i}^{T}=\left(1-\rho_{i}\right) u\left(y_{i}(1-t)-a_{i}^{T}\right)+\rho_{i} u\left(\left(r y_{i}+q_{i}^{T}\right)\right),
$$

where $q_{i}^{T}$ is the utility maximizing amount of topping up insurance bought by $i$, and $a_{i}^{T}$ the associated premium:

$$
q_{i}^{T}=\max \left(0, \arg \max _{q_{i}}\left(1-\rho_{i}\right) u\left(y_{i}(1-t)-a_{i}\right)+\rho_{i} u\left(r y_{i}+q_{i}\right)\right) .
$$

Note that $q_{i}^{T}$ is non-negative: It is not possible to sell social insurance coverage on the private insurance market. This perfectly realistic assumption is crucial for the main result that will follow.

Because social insurance pools risks across all agents and is financed by proportional taxes, the tax price will be non-actuarial to the advantage of high-risk agents 
and disadvantage of low-risk agents. In monetary terms, there will be net-receivers and net-payers, depending on the following inequality:

Definition 1. Agent $i$ is a net payer $\Leftrightarrow t\left(1-\rho_{i}\right) y_{i}>\rho_{i} r y_{i}$.

The model captures two potential motives for selfish individuals to support social insurance: The redistribution motive and the insurance motive. The redistribution motive can be traced back at least to Meltzer \& Richards (1981) and amounts to net recievers supporting social insurance because they gain monetarily from the redistribution. Less trivially, net-payers may support social insurance because of the insurance motive: If they are sufficiently risk avert and market insurance is sufficiently inefficient (in this model captured by $c$ being high enough), net-payers will prefer constitution S to $\mathrm{M}$.

Consider now how the preferences over the three constitutions are determined. For actuarially fair insurance, full insurance is optimal. But since social insurance is risk pooling, net payers have an ideal replacement level below 1, whereas net receivers would ideally prefer more than full social insurance coverage, though this is not allowed. ${ }^{2}$

Let $r_{i}^{*}$ denote the ideal social insurance replacement rate according to $i$ :

$$
r_{i}^{*}=\min \left(1, \arg \max _{r \in[0,1]}\left(E U_{i}^{S}\right)\right) .
$$

Net payers in any given social insurance scheme will ask if they would be better off under market insurance. The answer depends on the level of market inefficiency $c$. Define a special level of $c$ denoted $\widetilde{c}$, such that whenever $c<\widetilde{c}_{i}$ we know that $i$ will have $\mathrm{M}$ as her most preferred constitution.

Definition 2. For every agent $i$, such that $t\left(1-\rho_{i}\right)>\rho_{i} r, \widetilde{c}_{i}$ is the level of $c$ such that $c<\widetilde{c}_{i}$ implies $M \succ_{i} S$ for all $r \in(0,1]$ and $c=\widetilde{c}_{i}$ implies $M \sim_{i} S$ for $r=r_{i}^{*}$.

Note that $\widetilde{c}$ is only defined for net payers. Because net receivers have a positive return to social insurance there is no admissible $c$ for which the market alternative is always the most preferred alternative. Note however that net recievers may still prefer to buy topping up contracts if social insurance replacement rate is too low relative to their risk-aversion.

We now turn to political support, defined as follows:

Definition 3. For any given replacement rate $r$, the political support for social insurance, denoted PS, is the number of individuals who prefer $S$ or $T$ to $M$ :

$$
P S=\#\left\{i \in[1, N] \mid S \succsim_{i} M \text { or } T \succsim_{i} M\right\}
$$

Claim 1. Assuming that $T$ is not available, political support for social insurance will depend on $c$ and $r$ as follows:

\footnotetext{
${ }^{2}$ The fact that when insurance price is actuarially unfair, full insurance is never optimal was originally proved by Mossin (1968)
} 
a) if $c=1$, then $r=1$ maximizes political support for social insurance such that all net-recievers support social insurance and no one else does.

b) PS is weakly increasing in c for all $r \in(0,1]$.

Proof. a) If net-recievers would buy private insurance, they would buy full insurance at a actuarially fair price. With social insurance, they get full insurance at a price below what is actuarially fair, and hence no net-receivers will prefer market insurance. For the same reason, net-payers will never prefer social insurance. Lowering $r$ below 1 will never induce net-payers to support social insurance, but will induce net-recievers to prefer market insurance if the utility lost from insufficient coverage is bigger than the utility lost from having to accept fair premiums.

b) Follows because $\frac{\partial E U^{M}}{\partial c}<0$ and $\frac{\partial E U^{S}}{\partial c}=0$.

We are now ready to state the main result:

Proposition 1. When $T$ is available, PS is weakly decreasing in $r$.

Proof. First, note that net-receivers will always have TMS or TSM preferences. Thus, lowering $r$ will never induce a net-receiver to prefer $\mathrm{M}$ when $\mathrm{T}$ is available. Second, consider the preferences of net-payers as illustrated in the figure below:

FiguRE 2.1. How preferences depend on the replacement rate

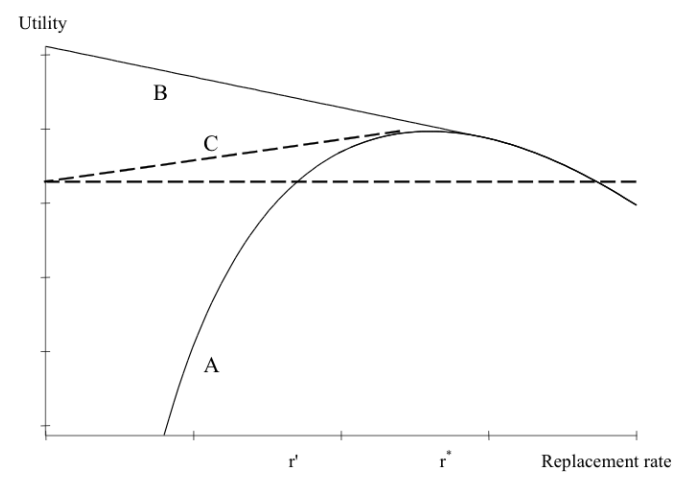

Curve A shows utility for a net payer with no topping up, which is maximized at $r^{*}$. Curves B and C illustrate utility when topping up is allowed under two different levels of $c$. For $c<\widetilde{c}_{i}, i$ will prefer only market insurance, and will for sure buy topping up when $r<r_{i}^{*}$ (curve B). For $c>\widetilde{c}_{i}$, (curve $\mathrm{C}$ ) private insurance is more expensive than social insurance, but when social insurance coverage is sufficiently below optimal, $i$ will nevertheless buy some topping up. For $r \in\left(r^{\prime}, r^{*}\right)$ the agent will have TSM-preferences, and for $r<r^{\prime}$, preferences will be TMS. The horizontal part of curve $\mathrm{C}$ is the utility from pure market insurance. 
Figure 1 illustrates the main conclusions of our analysis. Without topping up, policy makers can destroy the political support of net payers by setting the replacement rate either too high or too low. When topping up is allowed, political support can not be destroyed by a too low replacement rate. However, because of the impossibility to sell excess coverage from social insurance on the market, a too high replacement rate can still induce net payers to prefer pure market insurance.

\section{CONClUding Discussion}

The model presented in this paper can be seen as a partial explanation of the surprising resilience of universal welfare states such as those present on the nordic countries (cf. Lindbom and Rothstein, 2004). As shown, allowing topping up can be crucial for the political support for social insurance. Together with previous findings of Gouveia (1997) and Epple and Romano (1996), it is clear that the combination of minor cutbacks and allowing topping up is a viable strategy for policy makers who wish to maintain public support for universal welfare states. This finding helps us understand the continued public support for the extensive nordic welfare states. The generosity of social security in the nordic welfare states has decreased slightly, but remains higher than in other countries (Scruggs, 2006). In line with predictions from the theoretical model in this paper, private insurance to complement the welfare state have indeed been increasing ((Svensk Forsakring, 2010), and the support among voters for the high-tax welfare state holds remarkably steady (Svallfors, 2011). In all, it seems that the gradual mixing of private and public insurance does not contribute to the demise of welfare state, as once suggested by Butler and Germanis (1983), but rather contribute to the persistence of the welfare state. 


\section{REFERENCES}

Bergh, A. (2005) On the counterfactual problem of welfare state research: How can we measure redistribution?, European Sociological Review, 21, 345-357.

Butler, S. and Germanis, P. (1983) Achieving a 'leninist' strategy., Cato Journal, 3, $547-556$.

Casamatta, G., Cremer, H. and Pestieau, P. (2000) Political sustainability and the design of social insurance, Journal of Public Economics, 75, 341-364.

Epple, D. and Romano, R. (1996) Public provision of private goods, Journal of Political Economy, 104, 57-84.

Gouveia, M. (1997) Majority rule and the public provision of a private good, Public Choice, 93, 221-244.

Lindbom, A. and Rothstein, B. (2004) The mysterious survival of the swedish welfare state, Paper presented at the American Political Science Meeting, September 2004 .

Petretto, A. (1999) Optimal social health insurance with supplementary private insurance, Journal of Health Economics, 18, 727-745.

Scruggs, L. (2006) The generosity of social insurance, 1971-2002, Oxford Review of Economic Policy, 22, 349-364.

Svallfors, S. (2011) A bedrock of support? trends in welfare state attitudes in sweden, 1981-2010., Social Policy \& Administration, 45, 806-825.

Svensk Forsakring, . (2010) Forsakringar i sverige 2010, Annual report. 